\title{
SOBRE O DESENHO INFANTIL E O NÍVEL COGNITIVO DE BASE
}

\author{
Maria Lúcia Batezat Duarte (Dra.) $)^{1}$
}

\begin{abstract}
Resumo
Neste artigo o desenho infantil é relacionado aos esquemas do nível cognitivo de base. O objetivo é apresentar argumentos sobre a importância do desenho prototípico nos processos mentais de memorização, categorização e conhecimento. A teoria dos níveis de categorização cognitiva de Eleanor Rosch e a teoria da "imageria inicial" de Bernard Darras, são as principais referências juntamente com os desenhos de Gabriel, coletados por Giselle Ventura (2006) e arquivados no LabDIA.
\end{abstract}

Palavras-Chave: desenho infantil; representação gráfica; nível cognitivo de base; protótipos gráficos;

\section{Introdução}

Estávamos sentados em um bar do aeroporto esperando o nosso vôo. Muito atento, considerando seus 5 anos de idade, Felipe preenchia um álbum com figuras de animais. De repente ele levantou sua cabeça e encarando-me perguntou: - Como eu sei qual é o pato e qual é o cisne? Sem refletir respondi rápido: - O cisne tem o pescoço comprido. Felipe pareceu ter aprovado a resposta, porque imediatamente as figuras do pato e do cisne foram coladas no seu devido lugar.

"Cisnes têm o pescoço comprido" deve ter sido a primeira explicação que eu mesma recebi há muitos anos atrás quando, como ele, começava a diferenciar e classificar os objetos do mundo. Atualmente neurólogos e psicólogos denominam "sobre-apreendido" esse conhecimento primeiro, realizado na infância, e utilizado para sempre como base para novas liações (Ver para isso: Bideaud et all, 2004; Houdé, 2005). Outras informações, como aquela que eu dera a Felipe, povoaram rapidamente a minha mente: pássaros têm asas e voam; a girafa é muito alta; o leão ruge; o boi muge;... Penso que até hoje pais, tios, primos, babás, não avaliam muito bem a importância, o valor, e a permanência que essas primeiras e simples explicações diferenciadoras têm na nossa vida.

Frio/quente, alto/baixo, grande/pequeno, perto/longe, liso/rugoso, são algumas das qualificações utilizadas para agrupar e/ou diferenciar os objetos em infinitos jogos e exercícios utilizados nas salas de aula com os pré-escolares. Mecanismos cognitivos de classificação a partir de semelhanças e diferenças formais, altamente utilizados na

\footnotetext{
${ }^{1}$ Projeto de Pesquisa "As propriedades dos objetos e o desenho - um estudo teórico dos protótipos" A autora é a pesquisadora que executa o projeto (2007-2009), CEART/UDESC.
} 
infância, permanecem ativos ao longo da vida. Classificações são recursos mentais de facilitação e organização dos processos mentais de conceituação e pensamento.

Neste artigo defende-se a hipótese que o desenho, na infância, é um forte recurso cognitivo de reconhecimento, classificação e identificação dos objetos do mundo. É, também, um desenho figurativo (que figura os objetos) e realista (que apresenta os objetos experimentados concretamente pela criança). As bases desse pensamento serão apresentadas a seguir.

\section{Sobre imagem visual e conhecimento}

Até os anos setenta os lingüistas defendiam a idéia que as categorias cognitivas utilizadas pelos seres humanos para classificar os objetos eram intrinsecamente ligadas à linguagem em uma relação de causa e efeito. Isto é, acreditava-se que as categorias ou a classificação dos objetos existiriam apenas com, e em razão de, a linguagem. Acreditava-se também que, como a linguagem, categorias deveriam ser uma construção humana arbitrária. Investigando a orientação organizacional de tarefas propostas com objetos sem-nome, na população dos Dani, em Nova Guiné, Indonésia, Eleanor Rosch (1973), tornou inválida essa crença. Os Dani não possuíam palavras para as cores, apenas para a escuridão "mili" e para a claridade "mola", assim como não possuíam palavras para nomear as formas geométricas básicas: círculo, quadrado, triângulo. Rosch criou uma série de testes nos quais os Dani deveriam escolher e memorizar uma cor, ou figura geométrica, entre um conjunto de cores e figuras apresentadas. Como resultado os testes apontaram que as cores e formas escolhidas insistentemente eram sempre cores e formas consideradas básicas, as mais relevantes e salientes. Isto é, sem a referência do vocabulário verbal, os Dani respondiam aos testes indicando cores e figuras geométricas consideradas nucleares ou básicas para as populações cuja linguagem evidenciava essa primazia. Os processos cerebrais de seleção e memorização revelaram-se iguais à revelia do idioma, da presença ou ausência de vocábulo verbal para designar os objetos. Por exemplo, entre cartelas que apresentavam as cores: vermelho carmim, vermelho, vermelho alaranjado; ou vermelho, vermelho alaranjado, vermelho terra; a escolha dos Dani apontava para o "vermelho" puro, isto é, a cor básica. Igualmente escolhiam o "círculo", quando lhes eram apresentadas cartelas com desenhos de: ovóides, meio-círculo, círculo, círculo incompleto, etc.

As escolhas realizadas pelos Dani, baseadas na memorização dessa o aquela cor, dessa ou daquela forma visual, apontavam sempre para as entidades mais típicas 
(prototípicas), aquelas que são consideradas organizadoras ou centrais em uma sistematização categorial. É o vermelho puro que, em todas as línguas conhecidas, agrupa, reúne, todos os outros tons de vermelho, assim como é o quadrado (com seus quatro lados iguais) que reúne, agrupa, em uma categoria todas as figuras geométricas quadrangulares. Essa investigação e várias outras levadas a cabo ainda nos anos setenta, permitiram que Rosch afirmasse que:

“...devido ao modo como o sistema perceptual funciona, certas áreas no espaço da cor são mais salientes do que outras, e estas cores mais salientes são percebidas primeiro, são mais facilmente memorizadas e tornam-se protótipos em torno dos quais categorias de cores são formadas na cultura (e desse modo são ensinadas às crianças)" (Rosch, 1999, a tradução é minha)

Assim, segundo Rosch, independentemente do número de variáveis tonais ou de denominações que a cor "vermelho" possa adquirir em tal ou qual cultura haverá sempre aquele representante cuja tonalidade, brilho e pureza de pigmentação será considerado "O vermelho", uma cor prototípica, percebida primeiro, de mais fácil memorização em todas as culturas: um "vermelho" universal, apesar das variáveis lingüísticas (red, rojo, rouge, etc.). O que é universal, afirma Rosch "é a estrutura das categorias e o processo pelo qual os sistemas de categorias são formados" (Rosch, 1999).

Rosch é mundialmente reconhecida por sua teoria sobre os níveis de cognição ${ }^{2}$. Trabalhando sempre com objetos concretos, pertencentes ao cotidiano dos participantes das investigações, ela formulou três diferentes níveis de cognição relacionados a categorias mais ou menos amplas, mais ou menos abstratas. Ela utiliza o termo "abstrato" para significar o grau mais conceitual, mais ideativo de uma categoria. Vejase um exemplo:

\footnotetext{
${ }^{2}$ Os protocolos de investigação utilizados por Rosch, e pelos pesquisadores que continuaram ao longo de todos esses anos testando sua teoria, são frequentemente testes de seleção e identificação nos quais imagem visual e palavra deverão ser associadas, salvo no caso dos Dani, para quem não existia termo verbal correspondente às cores/formas que foram preferencialmente selecionadas.
} 


\begin{tabular}{|c|c|c|}
\hline $\begin{array}{c}\text { NÍVEL } \\
\text { SUPER-ORDENADO }\end{array}$ & NÍVEL DE BASE & $\begin{array}{c}\text { NÍVEL } \\
\text { SUB-ORDENADO }\end{array}$ \\
\hline \multirow{4}{*}{ Mobiliário } & \multirow{2}{*}{ Cadeira } & Cadeira de cozinha \\
\cline { 3 - 3 } & \multirow{2}{*}{ Mesa } & Poltrona \\
\cline { 2 - 3 } & \multirow{2}{*}{ Luminária } & $\begin{array}{c}\text { Mesa de cozinha } \\
\text { Estar }\end{array}$ \\
\cline { 3 - 3 } & & Luminária com pé \\
\cline { 3 - 3 } & & Luminária de mesa \\
\hline
\end{tabular}

Fig. 1. Esquema elaborado a partir de Rosch (1978, p. 30)

No exemplo elaborado a partir daquele fornecido pela autora (Rosch, 1978), o nível de cognição sub-ordenado é aquele no qual a imagem mental visual do objeto é a mais concreta e precisa. Dizer "cadeira de cozinha" implica referir-se a uma cadeira precisa, cuja configuração e uso são bem específicos. O sujeito que diz "cadeira de cozinha" não está se referindo a uma conceito de cadeira ou a uma cadeira qualquer.

Por outro lado, o sujeito que diz "cadeira" está se referindo exatamente a uma cadeira qualquer, a um conceito de cadeira. Refere-se, segundo Rosch, a uma cadeira abstrata que, nem você nem eu, somos capazes de precisar. Criamos uma imagem mental conceitual, porque conhecemos o sentido do termo em nossa língua, e sabemos que o sujeito falante esta se referindo a um objeto que utilizamos para sentar, que possui quatro pés, um assento e um encosto. Cadeira é um vocábulo/objeto do nível cognitivo de base por apresentar uma idéia, um conceito geral e abstrato.

A palavra "mobiliário" situa-se no nível Super-ordenado. É mais abstrata ainda, uma vez que nomeia um grande agrupamento de objetos e é, por isso, altamente imprecisa, indicando todo e qualquer objeto utilizado como mobília em qualquer tipo de ambiente habitado pelos seres humanos.

No sentido empregado por Rosch, uma categoria é uma reunião de objetos considerados equivalentes, similares, tendo como princípios: a) reunir o máximo de informação com o mínimo de esforço cognitivo (princípio da economia cognitiva); e, b) a informação veiculada é eficaz porque o mundo perceptivo chega até nós de modo estruturado e sistematizado muito mais do que de modo arbitrário ou aleatório (Rosch, 1978, p.28). (Foi a percepção de uma estrutura formal-visual que permitiu a Felipe compreender rapidamente aspectos de semelhança e diferença entre um pato e um cisne.) 
Após Rosch, são inúmeras as investigações sobre categorização e níveis de cognição ( por exemplo: Mandler e Bauer, 1988; Mandler, 1997; Cordier, 1983; Cordier e Labrell, 2000, Troatec, 1999, Richard, 2004). Para além dos níveis de cognição os testes comprovam que as crianças agrupam objetos preferencialmente por suas propriedades perceptivas (formais) ou funcionais (ações) sendo que as propriedades funcionais dependem do conhecimento já adquirido pela criança (Berger e Bonthoux, 2000).

Foram, certamente, propriedades formais (possuem asas, pés com membranas natatórias, corpo coberto de penas, corpo maior do que o corpo de um pássaro) e propriedades funcionais (nadam, voam) que fizeram Felipe aproximar e assemelhar pato e cisne. Mas, foi uma propriedade formal, o pescoço comprido, que permitiu a diferenciação.

Ao elaborar concepções sobre o funcionamento cerebral, os sistemas neurais, e a natureza privada da mente, Antônio Damásio (2000) anotou que os padrões neurais (formados a partir das modalidades sensoriais) e as imagens mentais (conjuntos de padrões neurais), são produtos tanto de processos cerebrais, quanto da realidade externa que os provocou. Ele refere-se assim à modalidade sensorial visual:

"Quando você e eu olhamos para um objeto exterior a nós, cada um forma imagens comparáveis em seu cérebro. Sabemos disso muito bem, pois você e eu podemos descrever o objeto de maneiras muito semelhantes, nos mínimos detalhes. Mas isso não quer dizer que as imagens que vemos [processadas no cérebro] sejam a cópia do objeto lá fora, qualquer que seja a sua aparência." (Damásio, 2000, p.405)

Jean-Piere Changeux, na conferência "Les universaux de la pensée" (Os universais do pensamento), esclareceu que para além das particularidades de cada sujeito, apesar das diferentes organizações conectivas entre neurônios e redes de neurônios que cada um de nós seja capaz de produzir (e, portanto, das diferentes significações que sejamos capazes de atribuir a um fato, um objeto, ou uma cena), todos nós ouvimos e registramos o mesmo som (mesmo que desconheçamos a língua falada) todos nós vemos e registramos a mesma face do sujeito que fala (ainda que sua fala tenha significados diferentes para cada um de nós). Isto quer dizer que "a despeito de um sistema nervoso variável de um indivíduo a outro, ele [o sistema nervoso] se constrói a partir de uma invariável" (Changeux, 2002).

No âmbito da produção de imagens visuais, Bernard Darras publicou em 1996 "Au commencement était l'image " livro no qual apresenta sua teoria sobre "imageria 
inicial" e analisa a produção inicial de imagens visuais. Darras aplica os argumentos teóricos e os níveis cognitivos, cunhados por Rosch no âmbito da linguagem verbal ${ }^{1}$, para a compreensão dos processos de produção de imagens visuais pelos sujeitos na cultura. Em seu estudo, o desenho infantil é enfatizado. Darras encontra equivalência entre o desenho infantil esquemático, repetitivo, irrefletido e "neutro" e os termos verbais (ou perceptivos) que Rosch havia situado no nível cognitivo de base.

"O nível de base fornece à demanda os esquemas gerais e consensuais que constituem as respostas padrão. As propriedades figurativas originárias deste resumo cognitivo são ao mesmo tempo as mais gerais e as mais distintivas. Elas oferecem, por outro lado, a incomparável vantagem de terem sido elaboradas a partir do consenso da comunicação usual." (Darras, 1998, p.88)

Esse pesquisador denominou "iconotipos" as imagens (ícones) típicas que configuram o nível de base da produção e comunicação com imagens visuais. Ele atribui a esse tipo de produção gráfica uma função, uma intenção comunicacional e não artística.

A partir das formulações teóricas de Rosch e Darras é possível considerar que:

1. Por economia cognitiva as informações obtidas no mundo físico são reunidas em classes e subclasses;

2. As classes e subclasses de objetos são organizadas com base nas experiências perceptivas (sensoriedade comum) e nas categorizações organizadas pela linguagem na cultura;

3. Essas classificações (categorizações) permitem o rápido re-conhecimento dos objetos do mundo físico e, portanto, a definição de procedimentos possíveis de interação entre os sujeitos e esses objetos;

4. Desenhos infantis (ou de adultos) realizados de modo esquemático apresentam, tal como a linguagem verbal, objetos genéricos e neutros, pertencentes ao Nível Cognitivo de Base.

\section{Desenho infantil e esquema gráfico}

Há precedentes, na história das teorias sobre o desenho infantil, no que se refere ao valor conceitual do desenho esquemático da criança. Luquet $(1913,1969)$ havia nomeado entre os elementos do desenho infantil, a presença e conservação de um desenho "tipo", indicando tanto a repetição de um modo gráfico específico para desenhar um mesmo objeto, quando a capacidade desse desenho tipo para representar 
uma pluralidade, uma vasta gama de objetos morfologicamente análogos. Luquet já associara ao "tipo" gráfico, a necessária presença mental de um "modelo interno", isto é, a memória de um modo específico utilizado para desenhar esse ou aquele conjunto de objetos (por exemplo: a figura humana e suas variáveis).

Igualmente, teóricos da arte relacionaram o desenho infantil com processos de conceituação. Em seu estudo Gombrich (1999) ressaltou a capacidade humana de reconhecer um objeto por meio de seus aspectos visuais formais mais privilegiados e relevantes. A essa síntese visual, Gombrich denominou "imagens mínimas" (Gombrich, 1999). De modo similar, Rudolf Arnheim (1980) compreendeu que a criança, ao desenhar, elabora um modo específico de registrar objetos e formular pensamentos. $\mathrm{O}$ desenho infantil é por ele concebido como um esquema de representação bidimensional das formas visuais cuja gênese demanda que "conceitos visuais" sejam traduzidos em "conceitos representativos" (Arnheim, 1980, p.156-159). O fato de o desenho infantil ser compreendido como planificação dos objetos e como uma representação gráfica relacionada às formas básicas e estruturais dessa planificação, parece essencial à idéia de desenho em si mesma e, também, à idéia de que este desenho contém, esquematiza, uma generalidade configuracional do objeto. $\mathrm{O}$ desenho infantil evoca os objetos como um esquema geral de uma categoria.

O termo "esquema" é utilizado por teóricos do desenho infantil, em especial por Lowenfeld (1977) e Arnheim (1980), para designar um tipo particular de desenho: aquele realizado de modo similar pelas crianças quando em fase inicial de suas experiências gráficas e pictóricas. Esse desenho, entretanto, como bem especifica Darras (1996, 1998), mantém-se útil e ativo para os sujeitos por um longo tempo em suas vidas.

Os esquemas gráficos são representações simplificadas e generalizantes dos objetos do mundo. Estudos comparativos entre os desenhos de crianças de vários paises já demonstraram que eles são muito similares e, além disso, mantêm essa similaridade através do tempo. Os desenhos infantis coletados por Luquet (1913, 1969), Wallon (1979), Lowenfeld (1977), Darras (1996) ou Duarte (1995) são muito semelhantes, no âmbito da configuração e da temática, apesar das várias gerações que separam as crianças que cada qual observou.

As razões para a produção e manutenção dos esquemas podem ser encontradas, do ponto de vista gráfico e conceitual, nas formulações teóricas de Georges-Henri Luquet (1913, 1969), Rudolf Arnheim (1980) e Ernest Gombrich (1999), conforme já citado. 
Entretanto, os estudos de Eleanor Rosch permitem (como fez Darras, 1996, 1998, 2003) relacioná-los a um processo cognitivo mais preciso: um processo de categorização por assemelhamento e distinção que, se reúne um conjunto mais amplo de propriedades dos objetos, encontra na percepção visual e nas propriedades físicas, formais, um bom recurso de identificação e classificação. Esse processo baseado na identificação de objetos típicos ou prototípicos, isto é, na relevância de um representante exemplar, proporciona que uma gama de objetos seja representada por meio de um único esquema gráfico, do mesmo modo como é nomeada por um único signo verbal. Trata-se então, de efetivar uma grande economia mental.

Quando um adulto aponta para a criança a figura de um coelho em um livro de histórias e diz a palavra coelho a criança aprende e repete a palavra utilizando-a não apenas para aquele coelho, mas para todos os pequenos quadrúpedes com orelhas longas e rabo pequeno (Newcombe, 1999, p.220). A criança percebe que a palavra designa, desenha, uma categoria de objetos.

Nos "esquemas gráficos" o objeto é apresentado tal como a palavra, denotando, na verdade, toda uma categoria de objetos cujas variáveis são assimiladas por meio de uma síntese simples e eficiente. Assim, a palavra ÁRVORE corresponde ao esquema gráfico "árvore". Ambos, em linguagens diferentes, apresentam um mesmo protótipo, paradigmaticamente significam qualquer tipo de árvore, qualquer árvore do mundo. Esse sentido múltiplo, esse caráter paradigmático passará a oferecer uma significação mais precisa apenas no entrelaçamento do discurso, na sintaxe construída para aquela fala específica, seja ela verbal ou gráfico-visual.

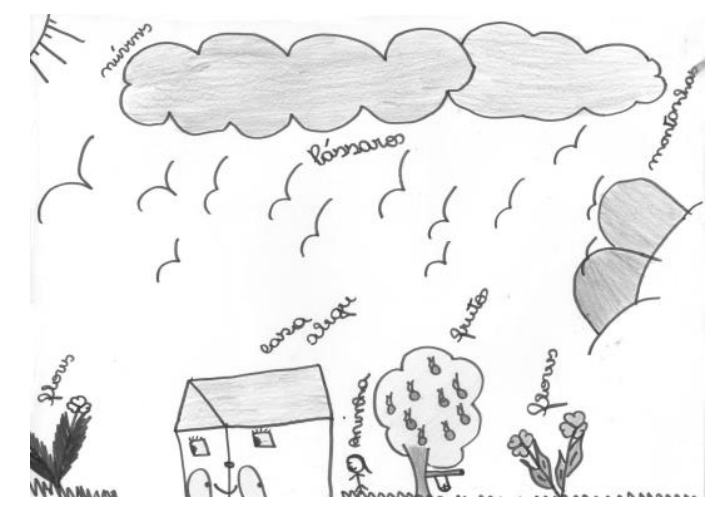

Fig. 2. Regina, 10a 
Com 6 anos e alguns meses Gabriel dispôs-se a relatar para Giselle Ventura como ele realizava os seus desenhos ${ }^{3}$. Realizou uma série de bichos, entre eles o elefante, a zebra e o gato apresentados abaixo. Sua fala explicando como desenhar indica claramente a relação classificatória e categorial que estabelece entre os animais. Ele demonstrou relacionar a configuração de animais quadrúpedes utilizando um mecanismo diferenciador e classificatório a partir das propriedades formais dos objetos. As associações tornam-se evidentes no seu relato e demonstram o seu processo cognitivo:
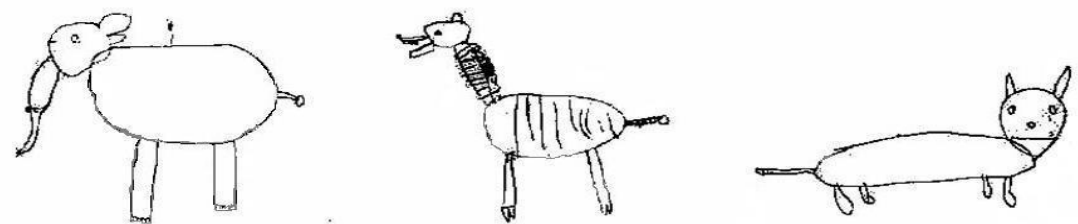

Fig. 3. Desenhos de Gabriel, 6a 5m: Elefante, Zebra e Gato

Fonte: arquivo LabDIA

- Pra fazer um elefante é bem fácil. É só fazer uma bola bem grandona. Faz uma cabeçona, aí faz uma... faz um narigão bem magrinho e aí faz dois buraquinhos faz as orelhas bem grandes, faz as patas dele que nem quadrados e façam umas toquinhas de ratos que são as unhas. Outra. Aí faz o mesmo. Faz um risquinho bem redondo e depois faz o mesmo que o leão só que bem pequenininho o rabo. Faz o rosto. Se quiserem fazer a boca dele é só não botar onde estão os olhos porque a boca e o nariz são separados. E aí é só colorir e pronto!

Parece evidente que, enquanto desenha, Gabriel exercita, realiza, introjeta uma identificação e um conceito sobre os animais desenhados. Como se, enquanto desenha, ele respondesse para si mesmo: - O que é um elefante? - O que é uma zebra? - O que é um gato? Ou como se, meio à maneira de Felipe, personagem do relato inicial deste texto, questionasse a si mesmo: O que diferencia um elefante de uma zebra, ou de um leão?

O desenho é, neste caso, realizado para identificar, diferenciar e classificar os objetos do mundo físico. Faz parte de um processo cognitivo de categorização.

\footnotetext{
${ }^{3}$ Os desenhos e comentários de Gabriel foram obtidos por Giselle Ventura enquanto aluna da oficina "O realismo no desenho infantil” 2006-1, CEART/UDESC. Fazem parte do acervo do LabDIA.
} 
Paralelamente aos desenhos de animais, Gabriel desenha personagens de desenhos animados. Martin Mystery é um personagem favorito.

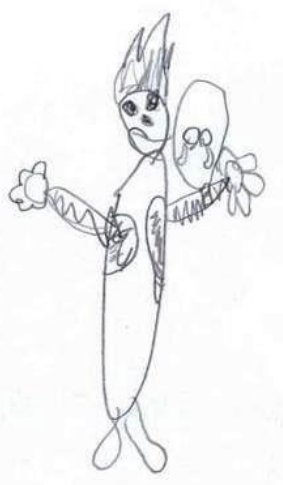

Fig. 4. Gabriel, 6a5m, "Martin Mystery" Fonte: arquivo LabDIA

- Pra fazer o Martin Mystery é fácil. Faz que nem a gente só que bem mais magro né, faz uma jaqueta com chamas. Depois faz que nem a gente, as mãos, com a jaqueta ainda pegando fogo, a jaqueta de chamas. Depois faz no pulso dele o relógio com uma imagem saindo dele, uma bolha saindo dele e vocês vão desenhar qualquer coisa que... tipo óculos alfa. Ai você faz a cabeça dele, a boca, os olhos, o nariz. E a coisa mais importante: o cabelo dele, que é bem arrepiado, porque é isso que faz ele ser o Martin Mystery. O cabelo dele é todo da cor de chamas e do jeito de chamas. E vocês vão lá, fazem a perna dele, fazem de novo. E é só colorir e tá pronto seu Martin Mystery.

Em seu relato sobre o desenho Gabriel vai identificando as propriedades físicas do personagem: o fato de ser magro; as roupas que veste; os recursos que lhe conferem poderes especiais (o relógio que capta imagens, os óculos de visão alfa). Mas, qual o processo cognitivo em curso nesse tipo de produção?

Para além das propriedades físicas diferenciadoras, ao construir o seu personagem herói, Gabriel pode estar elaborando esquemas de outra natureza. Martin Mystery não é um exemplar qualquer entre os seres humanos de gênero masculino. Martin Mystery é um personagem inventado (da/na cultura) e possui super-poderes. É um super-herói. Ele encarna outra tipologia ou modelo, encarna um "protótipo" de outra ordem, que não é biológica (como os animais) nem de artefatos humanos (como a “cadeira” no exemplo de Rosch). Trata-se de um protótipo de ordem psicológica, social e ética. Martin Mystery é poderoso, forte, corajoso. Ele protege e salva as pessoas, possui atributos humanos relevantes para a cultura de Gabriel. O caráter exemplar de Martin Mystery não é apenas de ordem física, formal, mas de ordem psíquica, moral.

\footnotetext{
${ }^{4}$ Martin Mystery é personagem título de História em Quadrinhos e Desenho Animado canadense.
} 
Torna-se, então, possível finalizar observando que, embora o desenho infantil seja essencialmente uma apresentação (física) de uma categoria de objetos, essa apresentação material efetivada em linhas e planos pode trazer para cena, presentificar, comunicar, a elaboração de esquemas mentais cognitivos de base ética e psíquica. Neste caso, são elaborados esquemas que evidenciam, mais propriamente, processos de identificação e constituição da criança, como sujeito, na sua cultura.

\section{Referências Bibliográficas:}

ARNHEIM, R.(1980) Arte e percepção visual. Uma psicologia da visão criadora. Trad. Ivone Terezinha de Faria. São Paulo: Pioneira e EDUSP. Primeira Ed. 1974.

BERGER, C. e BONTHOUX, F. (2000) Accès aux catégories par les propriétés : influences de la tâche et des connaissances chez le jeune enfant. In: CORDIER, F. e LABRELL, F. (org.) L'enfant et la catégorisation: le traitement des propriétés des objets. Psychologie Française, tome 45, n.2, p. 123-130.

BIDEAUD, J. HOUDÉ, O., PEDINIELLI, J-L. (2004) L'homme en développement. Paris: PUF.

CHANGEUX, J-P.(2002) Les universaux de la pensée. $443^{\circ}$ conférence de L'Université de tous les savoirs. 24 juillet. In : http://www.lemonde.fr/savoirs-etconnaissances/article/2002/07/03/jean-pierre-changeux-les-universaux-depensee 283523 3328.html acesso 16 fev 2008.

CORDIER, F. e LABRELL, F. (2000) L'enfant et la catégorisation: le traitement des propriétés des objets. Introduction. In: CORDIER, F. e LABRELL, F. (org.) L'enfant et la catégorisation: le traitement des propriétés des objets. Psychologie Française, tome 45, n.2, p. 103-112.

CORDIER, F. (1983) Inclusion de classes. Existe-t-il un effet sémantique ? L'année Psychologique. 83, 491-503.

DAMÁSIO, A. (2000) O mistério da consciência. Tradução Laura Teixeira Motta. São Paulo: Companhia das Letras. Primeira Ed. 1999.

DAMÁSIO, A. (2004) Como o cérebro cria a mente. Scientific American. Edição especial: Os segredos da mente, n. 4, p.6-11.

DARRAS, B. (1996) Au commencement était l'image. Du dessin de l'enfant à la communication de l'adulte. Paris: ESF Éditeur.

DARRAS, B.(1998) L' image un vue de l' esprit. Étude comparée de la pensée figurative et de la pensée visuelle. Recherches en communication, n.9, p.77-99.

DARRAS, B. (2003) La modélisation sémiocognitive a l'épreuve des résultas des neurosciences. Le cas de la production des schémas graphiques. Recherches en Communication. n.19, p.175-197.

DARRAS, B e DUARTE, M.L.B. (2007) Regards aveugles, mains Voyantes. Reliance - Revue des situations de handicap, de l'education et des sociétés. Lyon, France : Éditions Éres, n.25, septembre, p.54-63.

DUARTE, M. L. B. (1995) O desenho do pré-adolescente: características e tipificação. Dos aspectos gráficos à significação nos desenhos de narrativa. Tese de Doutoramento. São Paulo: ECA/USP.

DUARTE, M.L.B. (2004) Imagens mentais e esquemas gráficos: ensinando desenho a uma criança cega. In: MEDEIROS, Maria Beatriz (org) Arte em pesquisa: 
especificidades. Ensino e aprendizagem da arte e linguagens visuais. Brasília, DF: UnB, V2, p.134-140.

DUARTE, M.L.B.(2007) Representação, categoria cognitiva e desenho infantil. In: ROCHA, Cleomar (org) Anais do $15^{\circ}$ encontro Nacional da ANPAP Arte: limites e contaminações. Salvador: ANPAP, p.468-481.

GOMBRICH, E. H. (1999) Meditações sobre um cavalinho de pau e outros ensaios sobre a teoria da arte. São Paulo: EDUSP. Trad: Geraldo Gerson de Souza. Prikeira Ed. 1963.

HOUDÉ, O.(2004) La psychologie de l'enfant. Paris: PUF, 2004.

LOWENFELD, V. e BRITTAIN, W.L. (1977) Desenvolvimento da capacidade criadora. São Paulo: Mestre Jou. Trad. Álvaro Cabral. Primeira Ed. 1947.

LUQUET, G-H. (1913) Les dessins d'un enfant. Paris: Félix Alcan.

LUQUET, G-H.(1969) O desenho infantil. Trad: Maria Teresa Gonçalves de Azevedo. Porto: Ed. Minho. Primeira Ed. 1927.

MANDLER, J.M. e BAUER, P.J. (1988) The craddle of categorization: is the basic level basic? Cognitive Development, 3, 247-264.

MANDLER, J. (1997) Development of categorization: perceptual conceptual categories. In: BREMNER, G., SLATER, A. e BUTTERWORTH, G. (Eds) Infant development: recent advances. Hove, UK: Psychology Press, p. 163-189.

NEWCOMB, N.(1999) Desenvolvimento infantil. Abordagem de Mussen. Trad : Cláudia Buchweitz. Porto Alegre: Artes Médicas Sul. Primeira Ed. 1996.

ROSCH. E. (1973) Natural categories. Cognitive Psychology. n.4,p.328-350.

ROSCH, E. (1975) Cognitive representation of semantic categories. Journal of experimental psychology: General, n.104, p. 192-233.

ROSCH, E. (1978) Principles of categorization. In: ROSCH, E., LLOYD, B. (eds.) Categorization and cognition. N.J.: Hillsdale, p.27- 47, 1978.

ROSCH, E. (1999) Entrevista publicada in: www.dialogonleadership.org/Rosch1999.html, acesso em 21 abril 2008.

TROADEC, B. Le développement de la pensée chez l'enfant. Catégorisation et cultures. Toulouse : Press Universitaire du Mirail, 1999.

VENTURA, G. (2006) O desenhar de Gabriel. Trabalho de Conclusão da Oficina "O realismo no desenho infantil", Curso de Licenciatura em Artes Plásticas, CEART/UDESC. Ministrante: Maria Lúcia Batezat Duarte. 10p.

WALLON, H. (1979) Do acto ao pensamento. Ensaio de psicologia comparada. Lisboa: Moraes editores. Primeira edição 1942. 